\title{
The Relationship Between Emotion Regulation and Anxiety on Hemodialysis Patient in the Hemodialization Room of Rumah Sakit Al Islam Bandung
}

\author{
$1^{\text {st }} \mathrm{H}$ Firmansyah \\ High School of Health science \\ Aisyiah Bandung \\ Indonesia \\ anggriyana19januari@gmail.com
}

\author{
$2^{\text {nd }}$ AT Widianti \\ High School of Health science \\ Aisyiah Bandung \\ Indonesia
}

\author{
$3^{\text {rd }} \mathrm{P}$ Yualita \\ High School of Health science \\ Aisyiah Bandung \\ Indonesia
}

\begin{abstract}
Chronic Kidney Disease (CKD) consists of five stages in which the fifth stage is called End-Stage Renal Disease (ESRD), which requires replacement kidney therapy namely Hemodialysis (HD). Hemodialysis affects the physical and psychological condition. Psychologically, it will cause changes in the regulation of emotions and anxiety. The purpose of this study was to determine the relationship between emotion regulation and anxiety on hemodialysis patients in the hemodialysis room of Rumah Sakit Al-Islam Bandung. The researcher conducted the purposive sampling technique on 146 and used questionnaires in the form of a Likert scale in collecting data. Based on the study conducted in the Hemodialysis Room of Rumah Sakit Al Islam Chronic Kidney Disease (CKD) has five stages, the highest stage being the fifth stage. The fifth stage of CKD is usually familiar with End-Stage Renal Disease (ESRD), that is, damage to the kidneys accompanied by a decrease in the level of glomerular filtration (Glomerular Filtration Rate - GFR) which is less than $60 \mathrm{~mL} / \mathrm{min} / 1.73 \mathrm{~m} 2$ within a period of 3 months or more [1]. This stage of kidney failure therapy is needed to replace kidney function.

The number of ESRD patients from 2013-2016 in Indonesia significantly increased as many as $41 \%$. The number of patients experiencing End-Stage Renal Disease (ESRD) and undergoing hemodialysis (HD) in West Java based on etiology was $18 \%$ [2]. The increased rates of ESRD treatment known as Renal Replacement Therapy (RRT) accompanied the increase in ESRD. RRT in Indonesia in 2016 called CAPD was $2 \%$ (547 patients), HD was $98 \%$ (25446 patients), while West Java was on the first rank in the number of patients undergoing HD. From 2013 to 2018, there has been an increase in HD services of Rumah Sakit Al Islam (RSAI) Bandung by more than $100 \%$ from 12 to 34 machines. The hemodialysis unit of RSAI in August 2018 had 34 machines ready for being operated and one machine ready
\end{abstract}

Bandung, there was the relationship between emotion regulation and anxiety showing that a significance value of $p$ $=0.018$ which means $p<0.05$. There is a significant relationship between emotion regulation and anxiety in hemodialysis patients. Based on this study, it is recommended to form a group as a means of exchanging experiences among patients undergoing hemodialysis and make tools for the assessment of emotional and anxiety regulation.

Keywords-Emotion, Anxiety, Hemodialysis

\section{INTRODUCTION}

for being used in serving critical patients in the Intensive Care Unit (ICU).

Hemodialysis is not able to cure kidney failure, and cannot replace the function of the endocrine and the function of metabolism performed by the kidneys so that the lack of these functions will affect the patients' quality of life [3]. Improving the quality of life of HD patients can also be done by reducing the negative psychological aspects caused by the hemodialysis process. The patients can reduce those aspects if they choose good coping patterns so that patients will achieve adaptive emotion regulation [4]. Emotion regulation is the ability to take any action based on the level of perceived emotions so that someone can determine a good, tolerable and flexible attitude. The inability to regulate emotion causes a person to do something illogically and leads to the inability of deciding various contexts. [5](Gross, 2014). There are two types of emotion regulation, namely, positive (reappraisal) and negative (suppression) impacts [5]. The regulation of negative emotions will lead to anxiety and depression [6]. One of the emotion regulation disorders that always accompany ESRD patients is anxiety [7]. [8] stated that patients with ESRD undergoing hemodialysis experienced anxiety. There were 40 respondents (100\%) showing that 
eight $(25.8 \%)$ respondents having mild anxiety level, twenty-three respondents $(57.5 \%)$ having moderate anxiety level, and nine respondents $(22.5 \%)$ having severe anxiety level

Emotion regulation will also affect the level of anxiety. The lack of social and family support for a person will cause emotion regulation disorders, which will increase anxiety, depression, and somatic symptoms. [8]. The purpose of this study was to determine the relationship between emotion regulation and anxiety in hemodialysis patients at Rumah Sakit Al-Islam.

\section{METHOD}

This study used a correlational quantitative method connecting two variables with the sample as many as 146 patients undergoing hemodialysis from February to March 2019 .

A tool used in this study to measure emotion regulation was the Emotion Regulation Questionnaire (ERQ) adapted from an instrument developed [5] According to [9] the results of the validity test with Pearson Correlation showed that the value of the reliability coefficient 0.780 and 59 items of the statement was valid. The researcher assessed the anxiety level using the Hamilton Rating Scale for Anxiety (HRSA), developed by the Jakarta Biology Psychiatry group (KPBJ) in the form of Anxiety Analog Scale (AAS). Yul Iskandar in 1984 in his study measured the validity of AAS with a sufficient correlation of HRS A $(r=0.57$ $0.84)$.

\section{RESULT}

The table 1 showed that the most age undergoing hemodialysis was patients aged $56-65$ years old as many as $34.93 \%$. In the study, male subjects undergoing HD was more than female subjects. The distribution based on the characteristics of religion indicated that the majority were Muslim, while the distribution according to education level showed that the most were the subjects who graduated from senior high school. Based on the duration of HD, there were many subjects undergoing HD for 13 months-3 years as many as $31.51 \%$. According to the frequency of hemodialysis, the patients most often underwent HD twice a week

TABLE I. SHOWS THE CHARACTERISTIC DESCRIPTION OF THE SUBJECTS' STUDY.

\begin{tabular}{|c|c|c|c|c|}
\hline \multirow{2}{*}{ No } & \multirow[t]{2}{*}{ Variable } & \multirow{2}{*}{ Characteristics } & \multicolumn{2}{|c|}{ total } \\
\hline & & & $\mathrm{N}$ & $\%$ \\
\hline \multirow[t]{6}{*}{1} & \multirow[t]{6}{*}{ Age } & $17-25$ years old & 1 & 0.68 \\
\hline & & $26-35$ years old & 19 & 13.01 \\
\hline & & $36-45$ years old & 31 & 21.23 \\
\hline & & $46-55$ years & 32 & 21.93 \\
\hline & & $56-65$ years & 51 & 34.93 \\
\hline & & $>65$ years old & 12 & 8.22 \\
\hline \multirow[t]{2}{*}{2} & \multirow[t]{2}{*}{ Gender } & Male & 75 & 51.37 \\
\hline & & Girl & 71 & 48.63 \\
\hline \multirow[t]{2}{*}{3} & \multirow[t]{2}{*}{ Religion } & Muslim & 145 & 99.31 \\
\hline & & Non Muslim & 1 & 0.69 \\
\hline \multirow[t]{4}{*}{4} & \multirow[t]{4}{*}{ Last education } & Elementary school & 23 & 15.75 \\
\hline & & Junior High School & 24 & 16.44 \\
\hline & & Senior High school & 50 & 34,25 \\
\hline & & College & 49 & 33.56 \\
\hline \multirow[t]{4}{*}{5} & \multirow[t]{4}{*}{ The length undergoing HD } & $3-12$ month & 19 & 13.01 \\
\hline & & 13 Month -3 years & 46 & 31.51 \\
\hline & & $3.1-5$ years & 41 & 28.08 \\
\hline & & $>5$ years & 40 & 27.40 \\
\hline \multirow[t]{3}{*}{6} & \multirow[t]{3}{*}{ HD frequency } & $1 \mathrm{x} / \mathrm{mg}$ & 9 & 6.16 \\
\hline & & $2 \times / m g$ & 133 & 91.10 \\
\hline & & $3 \mathrm{x} / \mathrm{mg}$ & 4 & 2.74 \\
\hline
\end{tabular}

Based on the table II in this study, most subjects had negative emotion regulation as many as 78 people
$(52.74 \%)$. While The table 3 indicated that the most level of anxiety in this study was medium anxiety.

TABLE II. DISTRIBUTION OF RESPONDENTS BASED ON EMOTION REGULATION ( $\mathrm{N}=146)$

\begin{tabular}{|l|l|c|c|}
\hline \multirow{2}{*}{ No } & \multirow{2}{*}{ Emotion Regulation } & \multicolumn{2}{|c|}{ Total } \\
\cline { 3 - 4 } & & $\mathrm{N}$ & $\%$ \\
\hline 1 & Positive & 69 & 47,26 \\
\hline 2 & Negative & 77 & 52,74 \\
\hline
\end{tabular}

TABLE III. DISTRIBUTION OF RESPONDENTS BASED ON ANXIETY IN THE HEMODIALYSIS ROOM IN 2018

\begin{tabular}{|c|l|c|c|}
\hline No & \multirow{2}{*}{ Anxiety Level } & \multicolumn{2}{|c|}{ Total } \\
\cline { 3 - 4 } & & N & $\%$ \\
\hline 1 & No anxiety & 9 & 6.17 \\
\hline 2 & Mild anxiety & 59 & 40.41 \\
\hline 3 & Moderate anxiety & 78 & 53.42 \\
\hline 4 & Severe anxiety & - & - \\
\hline
\end{tabular}


The researcher analyzed the relationship between emotion regulation and anxiety using a correlational hypothesis test. The hypothesis test performed was the Spearman Rank correlational test because the data was not normally distributed. The table IV indicated the results of the analysis. The analysis showed a value of $p=0.018$, meaning that there was a significant relationship between emotion regulation and anxiety in hemodialysis patients.

\begin{tabular}{|c|c|c|c|c|}
\hline & & & Emotion Regulation & Worry \\
\hline \multirow[t]{6}{*}{ Spearman's rho } & \multirow{3}{*}{ Emotion regulation } & Correlation Coefficient & 1,000 & $.195^{*}$ \\
\hline & & Sig. $(2$-tailed $)$ & . & .018 \\
\hline & & $\mathrm{N}$ & 146 & 146 \\
\hline & \multirow{3}{*}{ Anxiety } & Correlation Coefficient & $.195^{*}$ & 1,000 \\
\hline & & Sig. (2-tailed) & .018 & . \\
\hline & & $\mathrm{N}$ & 146 & 146 \\
\hline
\end{tabular}

\section{DISCUSSION}

Emotion regulation is an intrinsic and extrinsic process to control and adjust the emotions at the right intensity to achieve a goal including the ability to manage feelings, physiological reactions, the way people think, and emotional responses, such as facial expressions, mannerisms and tone voice. Furthermore, the emotion regulation is a process, that can quickly calm down after losing control of the emotions so that the hemodialysis patients will experience changes in the positive or negative emotion regulation.

Based on the results of the study in the Hemodialysis room of Rumah Sakit Al Islam Bandung (RSAI) indicated that the hemodialysis patients experiencing positive emotional regulatory changes according to the score regulation of positive emotion were 69 respondents (47.26 $\%)$, while the respondents who had a negative emotion regulation were 78 respondents $(52.74 \%)$.

According to the observations in this study, when the researcher carried out the interview and the questionnaire data, several respondents said that when the respondents experienced a decreasing psychological condition or needed moral support, they did the dhikr and prayer. Some respondents said that sometimes without any reason, there was an emotional change on the respondents that ultimately did not want to do HD during the hemodialysis schedule. Another respondent said that he did not do HD for one month so that it had an impact on his illness.

From the explanation above, this study supported the previous study of Gillanders, Wild, \& Deighan's (2008) study entitled "Emotion regulation Affect" which confirms that emotion regulation occurs due to initial stress in the selection of emotional stages, which will have positive impact outcomes for hemodialysis patients. Reappraisal emotion regulation offers protection from ongoing stress so that individuals get positive emotional experiences, stronger social support, and greater wellbeing. Suppressing emotions that set the stages of the emotion regulation process will express less positive emotions, the use of poor social support, undisturbed feeling from family and friends, and a higher level of anxiety, depression, and somatization [8].

The adaptative process of emotion regulation from the study results consistent with the concept of Nakagawa (2017) showed that older adults experienced high levels of emotional well-being. Older participants (49-71 years old) reported that negative effects were lower than on younger participants, whereas positive influences did not correlate with age. Our study showed that the development of emotion regulation can explain the mechanism of daily influence that is stable throughout adulthood. The researchers must explore other forms of adaptive emotion regulation [9].

Based on the results of the study in the Hemodialysis Room of Rumah Sakit Al Islam (RSAI) Bandung showed that hemodialysis patients who did not experience anxiety were nine respondents $(6.17 \%)$, fifty-nine respondents $(40.41 \%)$ experienced mild anxiety levels, seventy-eight respondents $(53.42 \%)$ experienced moderate anxiety, but the researcher did not find the respondents with the severe anxiety.

According to the study conducted in the Hemodialysis Room of Rumah Sakit Al Islam Bandung, the relationship between emotion regulation and anxiety obtained the significance value of $p=0.018$ meaning that the value of $\mathrm{p}<0.05$. This study indicated that there was a significant relationship between emotion regulation and anxiety in hemodialysis patients.

The strength of the relationship between emotion regulation and anxiety was 0.195 , meaning that it was very weak, while the direction of the relationship between emotion regulation and anxiety variables in this study was positive. Thus, the more positive emotion regulation, the lower the anxiety level will be. Otherwise, if the regulation is a negative emotion, the anxiety level will increase.

The above explanation can support the results of previous studies, including the study from Amstadter (2008) entitled Emotion Regulation and Anxiety Disorder. The results of the study suggested that the possibility of emotion regulation plays an important role in the etiology and management of anxiety disorders [10].

Mennin (2005) said that emotional dysregulation model of the Generalized Anxiety Disorder (GAD) is the disruption arising from the convergence of the emotional reactivity and high-intensity level, dysfunctional metaemotion(e.g. reduced clarity and understanding of emotions), and maladaptive efforts to regulate emotions [11]. GAD is an anxiety disorder, determining anxiety apprehension and manifestations of anxiety signs and symptoms appear. The researcher concluded that the findings related to emotional dysregulation in GAD can reflect the existence of anxiety disorders.

According to Gross, (2014), emotion regulation may affect anxiety by five processes, namely the selection of 
situations, the change of situations, the deployment of attention, the change of cognitive and response [5]. The selection of situations is a process that an individual experiences a stressor when a grieving process occurs. Grieving is an emotional response to loss. The manifestations of that feeling are sadness, anxiety, nervousness, difficulty sleeping, breath shortness and so on [12].

There are five phases in the process of grieving in each individual. They are denial, anger, bargaining, depression, and acceptance. The process in this phase will affect changes in emotion regulation. Age, gender, changes in external outlook, environment, personality, parenting, and culture (environment) influence the selection of situations. If the process of an emotional situation selection is good, it will produce positive emotion regulation that will reduce the level of an individual's anxiety. This is consistent with the results of this study that there was a relationship between emotion regulation and anxiety which had a positive value if the emotion regulation was positive. The anxiety would decrease if emotion regulation was negative, and the anxiety would increase.

The results of the study in the Hemodialysis room of Rumah Sakit Al Islam (RSAI) Bandung indicated that the respondents had negative emotion regulation as many as $78(52.74 \%)$. Those respondents were more than the respondents experiencing a positive change in emotion regulation. Most respondents who experienced moderate anxiety levels were seventy-eight respondents $(53.42 \%)$. They were more than the number of respondents who did not experience anxiety and mild anxiety. Both distributions were directly proportional between the negative emotion regulation and a higher level of anxiety, namely moderate anxiety.

Castledine ( 2013) mentioned that life pattern changes in HD patients are a process of grieving or loss [4]. This is one of the stressors that occur in every HD patient so it will cause emotion regulation changes. The process of emotional change will express a variety of emotions (rejection, anger, bargaining, depression, and acceptance). That is a step in the acceptance of their disease started from the time of diagnosis, RRT and therapy. Dewi 2018 stated that patients undergoing hemodialysis can experience body image problems, self-concept, and anxiety [11].

The selection of emotional situations, the situation changes, the deployment of attention, and cognitive and response changes influence emotion regulation changes. This process will have an impact on changes in emotion regulation. Emotion regulation in HD patients is the positive and negative emotion regulation. Negative regulation will be a strong stressor so that the patients will experience an increase in anxiety [5]

\section{CONCLUSION}

The study's result indicated that the level of positive emotion regulation was lower than negative emotion regulation with a difference of less than $1 \%$. The difference was very small because of the nursing intervention in the Hemodialysis room of Rumah Sakit Al Islam Bandung to overcome emotion regulation. There was a collaboration between nurses and spiritual officers. They visited hemodialysis patients routinely, read asmaul husna, did prayers together during hemodialysis, and did gathering hemodialysis patients once a year. The nursing interventions can increase the positive emotion regulation so that it will also reduce anxiety levels. Mild anxiety is normative anxiety for every individual who experiences stressors so that the researcher assumed that the difference among the patients who were not anxious, at mild and moderate anxiety was $6.84 \%$ more than patients experiencing anxiety.

\section{REFERENCES}

[1] N. K. F. K. clinical, "KDQOI clinical practice guideline for hemodialysis adequacy: 2015 update," Am J Kidney Dis, vol. 66, pp. 884-930., 2015.

[2] I. r. Registry., "9 th Report Of Indonesian Renal Registry 2016," Program Indonesia Renal Registry, 2016.

[3] Smeltzer, Brunner \& Suddarth's textbook of Medical- Surgical Nursing, New York: Lippincott Williams \& Wilkins, 2014.

[4] G. Castledine, A. Close, P. Dawson, L. Cook, Laura-Jane, J. Randle and F. Coffey, Oxford Handbook of Emergency Nursing, United Kingdom: Oxford Publisher, 2017.

[5] J. J. Gross, Handbook of Emotion Regulation, Second Edition, New York: Guilford Press., 2014.

[6] R. Caninsti, "Kecemasan dan Depresi pada Pasien Gagal Ginjal Kronis yang Menjalani Terapi Hemodialisis," Jurnal Psikologi Ulayat, vol. 1, p. 207-222, 2013.

[7] Z. S. Goh and K. Griva, "Anxiety and depression in patients with end-stage renal disease: impact and management challenges - a narrative review," International Journal of Nephrology and Renovascular Disease, vol. 11, p. 93-102, 2008.

[8] J. Y. K. Jangkup.

[9] J. Y. K. Jangkup, C. Elim and L. F. J. Kandou, "Tingkat Kecemasan Pada Pasien Penyakit Ginjal Kronik (Pgk) Yang Menjalani Hemodialisis Di Blu RSUP Prof. Dr. R. D. Kandou Manado," Jurnal e-Clinic (eCl, vol. 3, pp. 599-605, 2015.

[10] S. Lewis, M. Wild, C. Deighan and D. Gillanders, "Emotion regulation, affect, psychosocial functioning and well-being in hemodialysis patients," American Journal of Kidney Diseases, vol. 51, pp. 651-662, 2008.

[11] D. E. Wati and I. Puspitasari, "Kekerasan Terhadap Anak, Penanaman Disiplin, Dan Regulasi Emosi Orang Tua," Varia Pendidikan, vol. 30, pp. 21-26, 2018.

[12] J. Middlehurst, “An Investigation into the Relationship Between Emotional Regulation, Coping Skills, and Undergraduate Student's Psychological Wellbeing," Manchester Metropolitan Univetsity, United Kingdom, 2019.

[13] A. B. Amstadter, "Emotion Regulation and Anxiety Disorders," J Anxiety Disord, vol. 22, p. 211-221, 2008.

[14] D. S. Mennina, K. A. McLaughlinb and T. J. Flanagan, "Emotion regulation deficits in generalized anxiety disorder,social anxiety disorder, and their co-occurrence," J Anxiety Disord, vol. 23, p. 866-871, 2009.

[15] T. Heather Herdman ; Shigemi Kamitsuru, NANDA International, Inc. Nursing Diagnoses: Definitions \& Classification 20152017,Tenth Edition, UK: Willey Blackwile, 2014. 